DOI: $10.17805 /$ trudy.2019.6.4

\title{
ВОСТРЕБОВАННОСТЬ ТРУДОВОГО ПОТЕНЦИАЛА МОЛОДЕЖИ В УСЛОВИЯХ РЫНКА
}

\author{
Л. О. Ромашова \\ Московский гуманитарный университет
}

Аннотация: В статье дан анализ рынка труда молодежи, определена категория «трудовой потенциал». Выявлены причины профессиональной невостребованности молодежи.

Ключевые слова: безработица; рынок труда; молодежь; трудовой потенциал; профессиональная подготовка

\section{DEMAND FOR YOUTH LABOR POTENTIAL WITHIN A MARKET ENVIRONMENT}

\author{
L. O. Romashova \\ Moscow University for the Humanities
}

Abstract: The article analyzes the youth labor market, defines the category of «labor potential.» The reasons of the lack of professional demand for youth are revealed.

Keywords: unemployment; labor market; youth; labor potential; vocational training

В сложный период социально-экономического развития России основными субъектами реформационного процесса является молодежь. Это связано с тем, что: во-первых, молодежь составляет значительную часть трудоспособного населения России (Россия в цифрах, 2019: 75) и является главным фактором модернизации общества; во-вторых, в молодежи заложен тот потенциал, который в дальнейшем будет определять главное и будущее современного общества, и от стартовых условий их деятельности зависит последующее развитие страны.

Тем не менее ситуация на молодежном рынке труда пока еще сложная и напряженная.

По данным Росстата, доля молодежи среди занятых в 2018 г. составила 19,5\%. Остается высокий процент безработных среди молодежи. В 2018 г. безработной молодежи от 15-29 лет составило 38,4\%. Безработных с высшим образованием составило 20,7\%, со средним профессиональным $39,4 \%$ (там же: 103). Доля молодежи среди безработных больше, чем удельный вес данной социально-демографической группы среди населения трудоспособного возраста (30,7\%) (там же: 75). 
Научные труды Московского гуманитарного университета 2019 № 6

При острой конкурентной борьбе на формирующемся рынке труда, наблюдается невостребованность молодых людей с полученными ими профессиональными знаниями, что говорит о некотором проявлении недоиспользования трудового потенциала молодежи. Выходит, что уровень образования для молодежи не является гарантом обустроенности в трудовой сфере. Большое количество выпускников учебных заведений не востребованы совсем на рынке труда, а и те которые работают в большинстве случаев не по специальности. Причины этого могут быть разными, в том числе и готовность выпускника работать или не работать по выбранной специальности. Формальный подход к выбору профессии, дальнейшая незаинтересованность и, соответственно, низкое качество усвоенных знаний приводят к тому, что, понимая свою некомпетентность, выпускник сам избегает работать в соответствующей его диплому области (Хохлова, 2018:95)

Переход предприятий в руки частных собственников ужесточил требования к профессионализму работников и наличию трудового стажа. Большинство предприятий новых форм собственности было создано путем акционирования государственных предприятий, а новые возникали в основном в сфере услуг, в частности в торговле. Соответственно и поменялись условиями найма.

Такие области, как промышленное производство, наука, медицина, за счет реформаций сокращают рабочие места, и лишь торговля остается практически открытой и доступной сферой деятельности для молодых людей.

Идет явный перекос занятости в сторону торговой деятельности $(19,1 \%)$ и низкой занятостью в научной, технической сфере $(4,1 \%)$, что влечет сменой ценностных ориентиров молодежи в профессиональной деятельности (Россия в цифрах, 2019: 89).

Напряженность на рынке труда также обусловлена отменой централизованного трудоустройства выпускников учебных заведений и слабой государственной поддержкой по вопросам молодежной занятости.

В силу того, что молодежная безработица принимает «застойный характер», молодежь должна осознать данное собственное положение и пытаться свои проблемы решать самой. И поскольку растет несоответствие между потребностями молодежи в рабочих местах и наличием таковых, поэтому у выпускников вузов и других учебных заведений наступает разочарование из-за невозможности трудоустроиться по избранной профессии.

Кроме того, наблюдается низкий уровень представлений у молодых о рынке труда, что формирует неадекватное понимание о своих возможностях. И здесь молодые люди сталкиваются с противоречивыми ситуациями. С одной стороны, отсутствие знаний о реалиях производственной и экономической жизни, но при этом у них присутствуют высокие амбиции. С 
другой стороны, молодые люди с низким уровнем самооценки и высокой самокритичностью принижают свои профессиональные возможности. Недооценка свей профессиональной компетенции, приводит к недоиспользованию своего трудового потенциала.

Трудовой потенциал представляет совокупность характеристик человека, определяющих его возможности в трудовой деятельности.

Основными компонентами трудового потенциала является совокупность образовательных, профессиональных и психофизиологических характеристик, формирующих трудовое поведение.

Образовательный потенциал включает теоретические знания, навыки делового общения, системный анализ кризисных ситуаций, мотивация к самообразованию, разносторонность, владение информационными технологиями и т. д.

Профессиональный: готовность к повышению квалификации, планирование и осуществление замыслов, профессиональное мастерство, предпринимательская ориентированность, интерес к труду и др.

Психофизиологический: энергичность, выносливость, работоспособность, тип нервной деятельности, здоровье и т. д.

Личностный потенциал: инициативность, ответственность за приятие решений, лидерские качества, коммуникабельность, умение управлять своими действиями, объективный самоконтроль, креативные способности, степень усвоения социальных норм и т. д.

Наличие четких профессиональных целей повышает шансы на успех в трудовой деятельности. Но в силу объективных и субъективных причин не всегда молодежь находит применение своим навыкам.

Более конкретные причины профессиональной не востребованности молодежи заключается в следующем.

Во-первых, не ориентированность молодежи в представляемых на рынке труда спросе на конкретные профессии и специальности. Молодежь в подавляющем большинстве, не осведомлена о способах трудоустройства, не имеет информации о возможностях заработать в свободное от учебы время, не знает, как упредить нежелательные социальные ситуации. А это все порождает беспомощность молодежи на рынке труда и в общественной жизни. Возникает противоречие между ориентацией молодежи на профессии, соответствующие ее возможностям и притязаниям, ее уверенностью в правильности выбора, с одной стороны, и несоответствием выбранной профессии и полученной профессиональной подготовки спросу на них на региональном рынке труда, с другой.

Во-вторых, молодежь в силу решения вопросов, связанных с финансовыми расходами на образование, личные нужды, развлечения рано присту- 
Научные труды Московского гуманитарного университета 2019 № 6

пает к работе. При этом занимают неквалифицированные рабочие места, но при этом с регулярным доходом. Как правило, это молодые до 24 лет с неполной занятостью, т. к. пытаются совместить учебу и работу.

B-третьих, молодежь порой испытывает трудности при первичном трудоустройстве. Выпускники учебных заведений работают не по специальности. Это ведет к бесполезной потере времени, дополнительных затрат на обучение, интеллектуальных сил, энергии, что в конечном счете отражается на не эффективном использовании своего трудового потенциала.

В-четвертых, уровень социально-психологического настроения снижается. У молодежи проявляется устойчивое беспокойство «не оказаться безработным», «быть уволенным», «не попасть под сокращение» и т. д. Это духовное состояние также сказывается и на трудовом потенциале.

В-пятых, высокая степень неопределенности, нестабильности в сфере труда и трудовых отношений, что формирует негативный фон в оценке молодежью своих будущих перспектив в плане профессиональной самореализации и формирования активного финансового поведения, применения различных стратегий в эффективном распределении доходов от трудовой деятельности (Аликперова, 2019: 236).

Таким образом, недоиспользование трудового потенциала проявляется в неориентированной профессиональной подготовке к социально-значимым перспективным профессиям; не востребованность получаемого образования и соответственно трудоустройство выпускников не по специальности; отсутствие ответственности, нерациональном распределении полномочий; слабой трудовой активности из-за социальной напряженности и неопределённости перспектив.

Молодежь с нераскрытым потенциалом образуют инертную среду, поэтому необходимо создавать благоприятные условия для самореализации личности. Но реализовать это сложно.

Во-первых, в атмосфере жесткой конкуренции идет борьба за профессионализм рабочей силы.

Во-вторых, неустойчивость рыночной конъюнктуры предъявляет высокие требования к профессионализму и качеству персонала, которые могут меняться в зависимости от спроса, а, следовательно, и не дают гарантии на перспективу.

B-третьих, рассогласованность с требованиями предприятий процесса подготовки специалистов.

B-четвертых, не совершенна система мотивации работников, нет увязки между получаемой прибыли с конкретными результатами труда.

B-пятых, социальная напряженность, безработица оказывают давление, как на работника, так и на организации различных форм собственно- 
сти. И у молодежи возникают сомнения в правильности сделанного выбора, снижение убежденности в необходимости учиться, переживания по поводу своих перспектив.

Без четкой разработанной программы по трудоустройству молодёжи будет и дальше усложняться ситуация по раскрытию ее трудового потенциала. Без серьезного изучения спроса и предложений рабочих мест и рабочей силы, изменений в мотивации труда и движения трудовых ресурсов можно усложнить итак неустойчивую ситуацию на рынке труда, как на уровне региона, так и внутри организаций.

На уровне организаций в рамках правильного использование трудового потенциала необходимо проводить, на наш взгляд, следующие мероприятия.

Во-первых, способствовать формированию и реализации таких производительных способностей, которые соответствовали бы современным запросам качества рабочей силы к конкретному рабочему месту.

Во-вторых, создавать специальные условия, стартовые возможности, при которых максимально оптимизировать трудовой потенциал работника.

B-третьих, проводить анализ и прогноз кадрового потенциала, а также планировать его с учетом рыночных перспектив.

B-четвертых, содействовать адаптации молодежи к нововведениям.

B-пятых, не противопоставлять интересы организации интересам работников.

На региональном уровне необходимо вовлекать молодежь в трудовую практику, помогать инициативной молодежи в реализации собственных проектов, обеспечивать рабочими местами выпускников учебных заведений и решать проблемы рынка труда молодёжи.

Таким образом, трудовой потенциал молодёжи является важным элементом формирования и развития производительных сил общества. Формирование и оптимальное использование его должно стать приоритетным направление выбора управленческих воздействий. От использования трудовых ресурсов, зависит стабильность и эффективность функционирования организаций, отраслей, регионов и в целом общества.

\section{СПИСОК ЛИТЕРАТУРЫ}

Аликперова, Н. В., Ярашева, А. В., Виноградова К. В. (2019) Мотивация трудового поведения молодежи как возможности для реализации финансовых стратегий // Экономические и социальные перемены: факты, тенденции, прогноз. Т. 12. № 1. С. 226-240.

Россия в цифрах (2019) Крат. стат. сб. / Росстат. М. 
Хохлова, М. Г., Хохлов, И. И. (2018) Молодежь на российском рынке труда // Мировая экономика и международные отношения. Т. 62. № 9. С. 88-96.

Дата поступления: 12.12.2019 г.

Ромашова Людмила Олеговна - кандидат социологических наук, доцент кафедры социологии Московского гуманитарного университета. Адрес: 111395, Россия, г. Москва, ул. Юности, д. 5. Эл. адрес: LOR7@yandex.ru

Romashova Lyudmila Olegovna, Candidate of Sociology, Associate Professor, Department of Sociology, Moscow University for the Humanities. Postal address: 5, Yunosti St., Moscow, Russian Federation, 111395. Email: LOR7@yandex.ru

\section{Для цитирования:}

Ромашова Л. О. Востребованность трудового потенциала молодежи в условиях рынка [Электронный ресурс] // Научные труды Московского гуманитарного университета. 2019. № 6. URL: http://journals.mosgu.ru/trudy/article/view/1095 (дата обращения: дд.мм.гг.). DOI: 10.17805/trudy.2019.6.4 